\title{
The Uncertain Definition of Diseases in the Light of Emerging Technologies
}

Simonato $L^{1^{*}}$, Baldo V ${ }^{1}$, Canova $C^{1}$ and Pegoraro $\mathbf{R}^{2}$

1Laboratory of Public Health and Population Studies, Department of Molecular Medicine, University of Padova, Italy

${ }^{2}$ Lanza Foundation, Padova, Italy

*Corresponding author: Simonato L, Department of Molecular Medicine, via Loredan 1835131 Padova, Italy, Tel +393479837201; E-mail: lorenzo.simonato@unipd.it

Received date: February 23, 2016; Accepted date: March 09, 2016; Published date: March 11, 2016

Copyright: ( 2016 Simonato L, et al. This is an open-access article distributed under the terms of the Creative Commons Attribution License, which permits unrestricted use, distribution, and reproduction in any medium, provided the original author and source are credited.

\begin{abstract}
The development of powerful new technological tools (especially in the field of molecular biology and the neurosciences) on the one hand, and of our potential for digitally recording huge amounts of information in every field (medicine included) on the other, is rapidly challenging the classic course of a diagnostic process based on the onset of symptoms prompting physical and instrumental exams and ultimately leading to a clinical diagnosis. The particular cases of screening and of incidental findings are also considered and discussed. Nowadays, the definition of a disease is increasingly related to the particular tools used to diagnose it more or less reliably and consistently across time and populations. This new and constantly evolving situation inevitably poses important ethical issues, such as individuals' right to keep their health-related information confidential, but also the responsibility of National Health Systems to the communities they serve. Life-long longitudinal studies based on electronic healthcare archives have been recommended for the purposes of exploring the impact of new technologies on the health profile of the general population, and the underlying unknown dimension of the real distribution of diseases in said population. An example of birth-cohort from North-East of Italy using electronic health archives is presented and discussed.
\end{abstract}

Keywords: Emerging technologies; Health information; Ethical aspects

\section{Introduction}

In their struggle for life, humans have always paid great attention to the diseases affecting their wellbeing, attributing them meanings that vary across historical periods and different populations, depending on their cultural, religious and scientific beliefs. We know now far more than in the past about the nature and origins of human diseases, but nobody would dream of concluding that all biologically existing diseases are known to the human sciences. This being the case, we have to admit that we are still not fully aware of the overall biological dimension of the diseases existing in the real world, their pathological characteristics, and the number of persons actually affected. Nor do we know the real relative size of all existing diseases, or the proportion of patients diagnosed with a given disease out of the number actually affected. It is therefore reasonable to assume that we should consider three different dimensions of disease: (i) the real underlying dimension, which is impossible to ascertain exhaustively using our present scientific tools; (ii) the clinical dimension, usually a diagnosis derived from recognized symptoms, or by screening programs conducted on asymptomatic subsets of the population, or due to incidental findings; and (iii) the population level, in which (unlike the former, which is basically a personal matter confined within the patient-physician relationship) the dimension of disease is measured by means of ad-hoc systems for recording data on the whole population. One particular approach used to investigate underlying, or undiagnosed, disease has been screening.

\section{Anticipating the Diagnosis: The Screening Approach}

The hypothesis that anticipating a diagnosis in asymptomatic individuals might improve their prognosis was investigated in the 1960s, focusing mainly on neoplastic disorders [1]. The results achieved so far have been satisfactory for cancers of the breast, uterine cervix, and colon, while no benefits or dubious results have been seen for several other types, such as prostate cancer [2]. Research is ongoing in this field and further scientific evidence to support screening will hopefully emerge. The efficacy of a screening program, sufficient to justify its application to the general population, must ultimately be demonstrated by a drop in the mortality rate of the population being screened. It is important to bear in mind that screening tests are not diagnostic per se; their purpose is to separate the screened population into two subsets: one testing positive, with a very high prevalence of the disease; the other testing negative, with a very low prevalence of the disease.

The term 'screening' is also commonly used, however, for the early diagnosis of established genetic conditions pathognomonic of a given disease, such as trisomy 21 or metabolic disorders. Unlike cancer screening (in which case a positive test result should prompt secondlevel diagnostic procedures), prenatal or neonatal screening for genetically-determined diseases is diagnostic, and is undeniably justified by improvements in the early and successful management of disease.

\section{Screening vs predicting: biotechnology}

The rapid development of biotechnology has introduced a new, more complicated concept of screening deriving from the availability of molecular tests, which are often offered on a commercial basis, for predicting a higher risk of chronic diseases or pathological conditions during an individual's life-time. This type of screening inevitably 
carries important ethical issues concerning the disclosure of information, the lack of a demonstrable health benefit, and the risk of triggering the stigmatization of individuals testing positive for a given condition. Unlike the previously-examined situations (in which the aim of screening is to identify the early signs of a disease), we are dealing here with the ability to pinpoint individuals at higher risk of developing a particular disease, or more susceptible to certain exogenous noxae. Such tests should not be introduced in public health practice before they have undergone a thorough scientific validation, documenting their sensitivity, specificity, and predictive values by means of appropriate population trials [3].

\section{Screening vs predicting: electronic population-based archives}

A third scenario that is increasingly attracting attention concerns the relationship between the availability of information and the identification of disease, based on the potential use of the vast amount of information generated by economic, commercial, mediatic, and health insurance systems. We can divide this field into two different settings: (a) the worldwide generation of non-specific information stored in big data archives, potentially suitable for disease-related actions, among others; and (b) information generated by modern national health services as part of their routine activities.

\section{Searching for disease using BIG DATA}

The increasingly widespread use of digital recording in administrative, commercial and social networks is opening up new, hitherto unpredictable scenarios that might also influence the definition of disease in a digital society. Weber and coll. addressed this issue in a recent paper [4], examining the feasibility of record linking between health-related archives and other electronic archives such as Facebook, Twitter, blogs, online shopping habits, GPS recordings of individual mobility, personal devices monitoring physical exercise, and so on. By developing appropriate algorithms, it would be possible: to identify subsets of the population at higher risk of developing diseases such as diabetes type 2; or to ascertain whether distances between homes and drugstores or hospitals influence people's health profile; or to see whether the characteristics shared by Facebook friends influence their individual health profiles; and so on. The possibilities are limitless, and inevitably give rise to ethical aspects in relation to human rights.

\section{Searching for disease using NHS archives}

In advanced societies, most of which have national health systems in place, ethical issues and the traditional approach to the medical management of disease at individual level increasingly affect the institutions where decisions are made and actions are taken for the population as a whole. Since the mid-1980s, developments in digital technology have enables the storage of health-related and any other information in the form of electronic records. This new situation has led to the storage of huge amounts of information concerning the health conditions of individuals in many countries, and particularly in those where a national health service has been operating. These data have been used mainly for administrative purposes by insurance companies, private hospitals, governmental agencies, or national health services, but they could be an important new resource for public health actions [5]. This situation was foreseen already in 1946 by the chief of the U.S. National Office of Vital Statistics, Halbert Dunn, who predicted that it would one day be possible to build a "book of life" comprising all the records of the events occurring in every single member of the community throughout their lifespan, by means of record-linkage technology [6].

In a number of countries, mainly in Western Europe, North America, Japan and Australia, the health conditions of the members of the community are considered a public matter for which each state takes responsibility. This approach to healthcare is based on the principle of solidarity, and has been formally organized since the end of WW2 in the form of national health services (NHSs), which are funded by ordinary taxation. There is epidemiological evidence of health parameters such as life expectancy or infant mortality worldwide [7] being best in the countries were a NHS has been activated. This is a key issue in modern medicine because it goes to show that the health of individuals is no longer a mere private matter between doctors and patients. An organized public health system is more effective in promoting health than a traditional system in which all health-related problems are left to the patient-doctor interaction.

The existence of a NHS has two important ethical implications, the first of which concerns the public system's responsibilities: if the NHS is the main determinant of the health of a population in a given country, its efficiency and efficacy should be systematically assessed and improved by means of reliable auditing and planning practices. Second, every time a citizen has health problems and takes advantage of the services offered by the NHS (drug prescriptions, hospital admissions, first aid, etc.), one or more electronic records are generated and stored in huge repositories, that are generally organized into different, physically separate, specific archives for administrative purposes; and individuals thus lose control of their own personal data because they cannot directly access the health archives.

This situation generates an important discrepancy between the private nature of personal health information and the data management needs of a modern NHS, which cannot exploit its store of information for health promotion purposes without using personal identifiers. The problem could be solved by extending the practice of obtaining informed consent to include the use of personal data, but this would only be a solution if the whole population, or almost, were to give their consent. If even small proportions - up to $10 \%$, for instance - were to withhold their consent, this would probably introduce a selection bias and would severely reduce the efficiency and efficacy of any health surveillance conducted by the NHS.

Another critical issue regards the architecture of the archives where different health information is stored. Generally speaking, we should consider a patient as a whole, the matrix of a combination of healthrelated characteristics. But the health information concerning (and consequently belonging to) a given individual is generally scattered instead among different electronic archives. The more complex the medical case, the more numerous the archives in which the related information will be dispersed, due to the way in which the systems used to record the information are generally organized, i.e. by data source rather than by individual. This is exactly the opposite of what Halbert Dunn was suggesting.

Hence the need to arrange for a second phase in which all the fragments of information concerning a given individual are combined to build the person's health profile. It is also important to bear in mind that the events occur dynamically over time, and what we wish to observe are the trajectories of an individual's state of health, which are necessarily embedded in a long-term flow of time.

In the last twenty years there has been an increasing number of experiences focusing on rebuilding personal health profiles from 
Page 3 of 4

records scattered in different archives, mainly within public health systems $[5,8,9]$. The reports in the scientific literature of such experiences gained with these meta-systems are characterized by the use of a variety of definitions and methodological tools, but they unavoidably have two characteristics in common: the population dimension and the record linkage practice. There should be no incompatibility between the building of health profiles on citizens individually assisted by a country's NHS and the life-long follow-up of population-based cohorts consisting of all the individuals belonging to the community served by the NHS. These two actions proceed in parallel and, in principle, they are under no temporal or spatial constraints (e.g. the size of the population) as long as the population exists and the NHS is operating.

\section{The time dimension: life-span observation}

Most of the diseases affecting the populations of industrialized countries are chronic conditions [10] that develop over long periods of time, often spanning several decades. We clearly need to adapt our tools to the phenomenon we wish to observe and the availability of health data routinely recorded by the NHS can serve as a novel, powerful tool not only for monitoring health profiles at general population level, but also for investigating the timing and the trajectories involved in the onset of a given disease in a given individual [11]. If we focus our attention on patients' prior history, what crucial combinations of health records are associated with the clinical diagnosis of a given disease? At what step in life might we be able to intercept a disease developing in a given individual?

Table 1 shows some results selected from a life-span study begun on the newborn in an area of north-eastern Italy as an example of the type of study that can now be conducted thanks to the digital records of health events obtained by a NHS [12]. In life-span studies, the observation should naturally start at birth, and the most effective way to study evolving population profiles presumably lies in conducting life-span prospective studies on the newborn. We ran a cohort study on all children born in Italy's Friuli-Venezia Giulia (FVG) region between January 1st 1989 (the first year for which electronic archives on attendance at birth became available) and December 31st 2011. The population living in this area benefits from a regional integrated healthcare system developed in the 1980s, which automatically collects and pools data on all healthcare funded by the NHS using a unique regional identification code. The birth cohort was identified from the FVG region's medical birth records (Certificati di Assistenza al Parto), which also report socio-demographic data on the parents, details of the pregnancy, labor and delivery, and the newborn's clinical characteristics at birth.

The results of the analysis (Table 1) conducted on the association between certain demographic and perinatal characteristics and the risk of developing asthma (the individuals affected were identified from prescriptions for asthma medication) point to a differential risk associated with some of the independent variables.

The follow-up of this birth cohort is currently being brought up to date with a view to confirming the preliminary findings and further investigating any changes in the health status of the members of this cohort.

\begin{tabular}{|c|c|c|c|}
\hline \multirow[t]{2}{*}{ Risk factor } & & & \multirow[b]{2}{*}{$\begin{array}{l}\text { P-value } \\
\text { (Pearson's } \\
\text { chi-square) }\end{array}$} \\
\hline & $\begin{array}{l}\mathbf{N}^{\circ} \text { of } \\
\text { asthmatic } \\
\text { children (\%) } \\
\text { (Tot=34,957) }\end{array}$ & $\begin{array}{l}\mathbf{N}^{\circ} \quad \text { of } \quad \text { non- } \\
\text { asthmatic } \\
\text { children }(\%) \\
(\text { Tot }=108,206)\end{array}$ & \\
\hline \multicolumn{4}{|l|}{ Sex } \\
\hline $\begin{array}{l}\text { male } \\
\text { female }\end{array}$ & $\begin{array}{l}19,268 \\
(55.12) \\
15,689 \\
(44.88)\end{array}$ & $\begin{array}{l}53,255(49.22) \\
54,951(50.78)\end{array}$ & $<0.001$ \\
\hline \multicolumn{4}{|l|}{ Type of delivery* } \\
\hline $\begin{array}{l}\text { spontaneous } \\
\text { elective cesarean } \\
\text { emergency cesarean } \\
\text { other^ }^{\wedge}\end{array}$ & \begin{tabular}{|l|}
11,857 \\
$(67.91)$ \\
$2,179(12.48)$ \\
$2,221(12.72)$ \\
$1,203(6.89)$
\end{tabular} & $\begin{array}{l}49,207(70.40) \\
8,021(11.48) \\
8,188(11.71) \\
4,481(6.41)\end{array}$ & $<0.001$ \\
\hline \multicolumn{4}{|l|}{ Birth weight (grams) } \\
\hline $\begin{array}{l}<2,500 \\
\geq 2,500\end{array}$ & $\begin{array}{l}2,207(6.31) \\
32,750 \\
(93.69)\end{array}$ & $\begin{array}{l}5,804(5.36) \\
102,402(94.64)\end{array}$ & $<0.001$ \\
\hline Gestational age $>3629-35<$ & \begin{tabular}{|l}
33,174 \\
$(95.64)$ \\
$1,360(3.92)$ \\
$152(0.44)$
\end{tabular} & $\begin{array}{l}103,758(96.60) \\
3,437(3.20) \\
216(0.20)\end{array}$ & $<0.001$ \\
\hline \multicolumn{4}{|l|}{$\begin{array}{l}\text { Maternal age at birth } \\
\text { (years) }\end{array}$} \\
\hline $\begin{array}{l}\leq 24 \\
25-29 \\
30-34 \\
35-39 \\
\geq 40\end{array}$ & \begin{tabular}{|l|}
$2,889(8.26)$ \\
$9,726(27.82)$ \\
13,822 \\
$(39.54)$ \\
$7,203(20.61)$ \\
$1,317(3.77)$
\end{tabular} & \begin{tabular}{|l}
$10,163(9.39)$ \\
$27,048(25.00)$ \\
$40,977(37.87)$ \\
$24,823(22.94)$ \\
$5,195(4.80)$
\end{tabular} & $<0.001$ \\
\hline \multicolumn{4}{|l|}{ Mother's formal education } \\
\hline $\begin{array}{l}\text { up to } 8 \text { th grade } \\
\text { up to } 13 \text { th grade } \\
\text { university }\end{array}$ & $\begin{array}{l}5,130(14.94) \\
17,009 \\
(49.55) \\
12,189 \\
(35.51)\end{array}$ & $\begin{array}{l}20,492(19.21) \\
52,574(49.29) \\
33,590(31.49)\end{array}$ & $<0.001$ \\
\hline $\begin{array}{l}\text { Hospital admissions for } \\
\text { respiratory infections in first } \\
\text { year of life }\end{array}$ & $1,059(3.03)$ & $2,015(1.86)$ & $<0.001$ \\
\hline
\end{tabular}

Table 1: Demographic and perinatal characteristics of children with and without asthma.

\section{Concluding Remarks}

The development of powerful new biotechnologies (especially in the area of molecular biology and the neurosciences), and of our capability for digitally recording vast quantities of information in all fields (medicine included) is rapidly challenging the diagnostic procedures adopted to date, based on the onset of signs and symptoms, followed by physical and instrumental exams that ultimately result in a clinical 
diagnosis. Modern diagnostics also caters for the early identification of genetically-determined pathological conditions such as Down's syndrome and trisomy 21 . Then there is the practice of using screening methods to anticipate a diagnosis when the patient is still asymptomatic, which has been validated by its positive impact on the mortality rates for some (mainly neoplastic) diseases. But even screening is still in the realms of established clinical diagnostics, and in the sphere of ordinary medical practice.

Emerging technologies are increasingly influencing the medical sciences, however, and particularly the feasibility of detecting an existing biological condition predisposing to a pathology, or identifying susceptible individuals in the population. In this developing field, we can distinguish between three different pathways : i) molecular biology tests for predicting the development of a given disease; ii) record-linkage between BIG DATA archives of various origins (commercial, economic, institutional, social networks, etc.) resulting in the definition of subsets of the population to consider at higher risk of developing a disease; and iii) record linkage between electronic administrative health archives, which could be processed using disease-specific algorithms to identify individuals with disease amidst a general population.

Smart citizens living in the smart cities of the future and using their smart devices will contribute an enormous amount of information that could also be used for public health purposes. This new scenario has its potential pros and cons, some of which relate to ethical matters such as confidentiality, the right to remain invisible, the risk of inappropriate or even criminal uses of the data, the stigmatization of individuals with certain characteristics. But it may also give us the chance to discover subsets of population at higher risk of certain diseases, assure a more efficient patient management, and maybe even reveal hitherto unknown pathways to the onset of disease.

Legislators should naturally aim to protect individuals against any misuse of people's health records, but this could prove difficult if central servers are relocated to foreign countries, as is often the case.

Restricting the matter to medicine, two recommendations could be advanced: the first concerns the need for a scientific assessment of the impact on a population's health status of the introduction of new diagnostic tests and tools; the second relates to the first, and concerns the implementation of population-based cohort studies, bearing in mind that monitoring chronic diseases (which are predominant in industrialized countries) demands a life-long follow-up. It is only by means of a long-term observation of the general population that we might be able to interpret the complex relationship between the (apparent) absence and the presence of a given disease.

\section{Acknowledgement}

The project Ethics and Emerging Technologies: a Population-based Health Monitoring Project is financially supported by the Foundation Cassa di Risparmio di Padova e Rovigo (CARIPARO) with a research grant.

\section{References}

1. Morrison AS (1992) Screening in Chronic Disease. Oxford University Press, New York.

2. Schroder FH, Hugosson J, Roobol MJ, Tammmela TLJ, Zappa M, et al. (2014) Screening and prostate cancer mortality: results of the European Randomised Study of Screening for Prostate Cancer (ERSPC) at 13 years of follow-up. Lancet 384:2027-2035.

3. Juth N, Munthe C (2012) The ethics of screening in healthcare and medicine: serving society or serving the patient? International Library of Ethics Law and New Medicine 51.

4. Weber GM, Mandl KD, Kohane IS (2014) Finding the missing link for big biomedical data. JAMA 311: 2479-2480.

5. Lyons RA, Ford DV, Moore L, Rodgers SE (2014) Use of data linkage to measure the population health effect of non-health-care interventions. Lancet383:1517-1519.

6. Dunn HL (1946) Record Linkage. Am J Public Health Nations Health 36: 1412-1416.

7. World Health Statistics 2015.

8. Simonato L, Baldi I, Balzi D, Barchielli A, Battistella G, et al. (2008) Objectives, tools and methods for an epidemiological use of electronic health archives in various areas of Italy. Epidemiol Prev 32: 5-14.

9. Holman CD, Bass AJ, Rosman DL, Smith MB, Semmens JB, et al. (2008) A decade of data linkage in Western Australia: strategic design, applications and benefits of the WA data linkage system. Aus Health Rev 32: 766-777.

10. WHO Global Status Report on Non-Communicable Diseases 2010.

11. Ichter M, Blane D (2013) The life course: challenges and opportunities for public health research. Int J Public Health 58: 1-2.

12. Pitter G, Ludvigsson JF, Romor P, Zanier L, Zanotti R, et al. (2015) Antibiotic exposure in the first year of life and later treated asthma, a population-based birth cohort study of 143,000 children. Eur J Epidemiol 31: 85-94. 